Laboratorio de Arte,2-1989 http://dx.doi.org/10.12795/LA.1989.i02.19

\title{
DON FRANCISCO MURILLO HERRERA
}

\author{
por MARIA Jose del CASTILlo y UTRILla
}

Estábamos en la Rebotica de la Farmacia de Murillo, en la Plaza del Salvador, frente a la Iglesia, justo al lado de los viejos soportales.

En aquélla Farmacia antigua, con anaqueles de madera y botes de cerámica blanca, Don Francisco Murillo Campos, me habla de su tio, de aquél señor eternamente vestido de negro, a quien conocí no se cuanto tiempo atrás, cuando yo aún no había hecho la Primera Comunión.

Aquél señor se llamaba Don Francisco Murillo Herrera, había sido Catedrático de Teoría de la Literatura y de las Artes en la Universidad de Sevilla y en ella había fundado el Laboratorio de Arte en el año de 1908.

Claro está que yo entonces, de todo esto, no tenía ni idea. Como tampoco tenía ni idea de que andando el tiempo, habría de tenerlo por el Maestro, el gran y lejano maestro, al que generación tras generación de Historiadores del Arte, debemos agradecimiento.

Por eso ahora, quiero recoger aquí algunos datos sobre su personalidad, sus costumbres, su perfil humano y las pequeñas anécdotas de su vida, sin otra pretensión que la de que su memoria no se pierda en el olvido de los que somos y en el futuro serán, miembros del Laboratorio de Arte Francisco Murillo Herrera.

En la Farmacia, en una mañana apacible, entre libros, carpetas y fármacos, Don Francisco Murillo, me cuenta cosas de su tio, al que cariñosamente llama «el tito Paco».

Como en toda buena conversación, se van entremezclando datos, observaciones. A veces se superponen fechas e historias; se deriva hacia derroteros que nos desvian del personaje principal. Pero esto no tiene importancia, al contrario, enriquece el conocimiento del entorno, da vida a la narración, a la vez que nos aleja de la fria exegesis científica, en la que por desgracia caemos con tanta frecuencia.

Don Francisco Murillo Herrera nació en 1879, fue miembro de una familia numerosa. Fueron siete hermanos, todos ellos varones, nacidos del matrimonio de Don Francisco Murillo Hernández y Doña Magdalena Herrera Espiner. 
Era Doña Magdalena sobrina del Obispo Herrera, que por entonces, hacia 1860, ocupaba la sede de Málaga, y quien bendijo el matrimonio, y Don Francisco, era farmacéutico, establecido en Vélez Málaga, donde nacieron todos los hermanos Murillo Herrera: Enrique, Francisco, Aurelio, José, Camilo y otro Aurelio, nacido el segundo, que murio muy niño, además de uno llamado Emilio que también se malogró.

Cuando los muchachos tuvieron edad de cursar estudios, la familia se trasladó a Sevilla, por considerar el matrimonio que en esta ciudad tendrían más facilidad para hacer una carrera.

Aquí se establecieron en el barrio de Triana, en una casa de la Plaza del Altozano, justo en el número 9, donde el padre abrió la Farmacia.

La vida familiar y la formación de los hermanos debió ser muy peculiar, demostrando el padre unas dotes de educador poco comunes, ya que no contento con dar a sus hijos una carrera universitaria, inculcó en ellos la responsabilidad moral del trabajo, y además, les dió un oficio, para que en caso de fracasar en los estudios superiores, pudieran ganarse con decencia la vida.

Este afán de educación lo extendió de igual manera a sus ayudantes en la Farmacia, obligándoles a que hicieran alguna carrera, y no pocos médicos, abogados y farmacéuticos salieron de aquélla casa del Altozano.

El último de los viejos mancebos que respondían a la antigua escuela, al menos, que yo recuerde, fué Isaac, que en la Farmacia del Salvador ya entre despacho y despacho, se hizo Profesor Mercantil.

En cuanto a los hijos del viejo farmacéutico, como deciamos antes, les proporcionó la siguiente formación: el mayor, Enrique, fue farmacéutico y mecánico; Francisco, siempre tal vez inclinado al campo artístico, hizo Farmacia, Derecho y Filosofía y Letras, y como oficio, pianísta. Al tercero de ellos, Aurelio, además de la carrera de Farmacia, le fomentó su afición a la pintura, proporcionándole estudios sobre este arte, en el que fue notable en el campo de los bodegones y retratos. El cuarto, José, fue Doctor en Medicina y como oficio tenía el de carpintero, y creo, según me cuentan, que la ebanistería fina era su especialidad. Por último, el más pequeño, Camilo, también Doctor en Medicina, tenía como especialidad la electricidad, para la que se mostró muy hábil.

Como podemos deducir el ambiente en que se desarrollo la adolescencia y primera juventud de D. Francisco Murillo Herrera, debió ser de responsabilidad y trabajo, sin cargas innecesarias, pues comenta su familia que siempre fue afable e incluso alegre, hasta que enviudó. Esta circunstancia no le hizo perder su afabilidad, aunque si su alegría.

Su esposa, Dolores Vega, era una mujer que tenía fama de guapa, era hija de un general y Don Francisco estaba enamoradísimo de ella, pero poco más de un año de haberse casado, murió a consecuencia de un mal parto. Desde entonces el viudo vistió siempre de negro.

Había estudiado Murillo Herrera las carreras de Derecho y de Filosofía y 
Letras en la Universidad de Sevilla, carreras que inició en 1893, a los catorce años y en las que se licencia en 1899, alternando estos estudios con los de Farmacia, de los que se licenció en 1917 en la Universidad de Granada.

El curso siguiente al de su Licenciatura en Filosofía y Letras, entró como auxiliar de Cátedra en la de Arte de esta Universidad, pasando a ser catedrático de esta materia, mediante oposición, en 1903.

Esta labor universitaria, la vino realizando ininterrumpidamente hasta su jubilación, y aún después, en las tertulias en que se reunía con sus antiguos alumnos, muchas veces en la Farmacia del Salvador, seguía ejerciendo su magisterio.

Pero la inquietud científica de Don Francisco Murillo, hizo que, antes de centrarse definitivamente en los estudios artísticos y de que hiciera de ellos su profesión, tanteara otros terrenos.

Su primera intención, una vez licenciado en Filosofía y Letras, fue dedicarse a la Filología, concretamente a la Lengua Arabe, tanto clásica como vulgar, impulsando por las enseñanzas de D. Federico de Castro y por las de D. Joaquín Azaña la Rúa. Pero influenciado por su maestro D. José Segalá Estalella, tomó el camino de las Artes, por el que todos le conocemos, matriculándose en la asignatura de «Teoría de la Literatura y de las Artes» en 1901, una vez licenciado.

Cuando opositó a la que sería su Cátedra de «Teoría de la Literatura y de las Artes», (cuyo programa comprendía: Arquitectura, Escultura, Pintura, Música y Literatura) ocurrió una anécdota bastante particular en el ejercicio llamado Trinca. La cosa fue así: Estando haciendo un ejercicio de Historia de la Música, el contrincante de Don Francisco, le refutó una opinión acerca de una pieza, posiblemente de Mozart. En esas diatribas en que se convertía el famoso ejercicio (del que Murillo Herrera fue siempre enemigo, por considerarlo de falta de compañerismo), tomaron parte algunos miembros del Tribunal. Para acabar la cuestión, Don Francisco se ofreció a interpretar la obra musical al piano y así lo hizo. La Catedra fue suya, y sindudar por un instante de sus otros méritos, tal vez la formación complementaria que le proporcionó su padre en la casa del Altozano, contribuyera a conseguir su asentamiento definitivo en la Universidad.

A partir de este momento, su vida fue la Facultad, en la que tenía un despacho pequeño junto a su aula. Allí se pasaba la vida, de diez a doce horas diarias. Allí atendía a alumnos, compañeros y a cuantas personas, por un motivo u otro llegaban a consultarle.

En la Universidad de la Calle Laraña, formó a Don Diego Angulo, a don José Hernández Díaz, a Don Antonio Sancho Corbacho, a tantos y a tantos, y a don José Guerrero Lovillo, por el que, sin duda, sentía una especial predilección, «casi un afecto paternal», me dice D. Francisco Murillo Campos. "Ya ves, niña, que yo era el único ahijado del tito Paco, y a Pepe Guerrero lo quería casi tanto como a mi». 
La verdad es que parece ser que el maestro sentía un afecto grande por todos sus alumnos, pero también tenía un alto sentido de la justicia, estos rasgos de su carácter se ven reflejados en otra pequeña historia que nos va a servir como ejemplo. Tenía Don Francisco un sobrino que estudiaba Filosofía y Letras por libre, en Algeciras. Parece ser que era muy querido por su tío, y que cuando venía a los exámenes, se hospedaba en su casa, como si fuera la propia. Pero es de sospechar que el muchacho no era demasiado aficionado al estudio, porque en cuatro convocatorias consecutivas, el sobrino se volvió a su pueblo con un suspenso en Historia del Arte en el bolsillo, y la papeleta la firmaba Murillo Herrera.

Tampoco el Infante Don Carlos, el hijo de Don Carlos y Doña Luisa, salía demasiado bien parado en los exámenes de Don Francisco, a pesar de que el muchacho tenía una enorme afición al arte y era un buen dibujante.

Mas de un notable, no obutvo en la asignatura de Historia del Arte. No obstante mantenían unas relaciones de lo más cordiales, y cuentan que en una ocasión, durante una entrevista, de las tantas que el profesor mantenía con sus alumnos, Murillo Herrera se quedó sin tabaco. Como buen fumador que era, se encontró un poco nervioso, y el interlocutor, que era precisamente el infante, no solamente le ofreció el cigarro, sino que le regló la pitillera en que llevaba el tabaco, una preciosa pitillera de plata que Don Francisco guardó como «el recuerdo de un querido alumno», hasta el fin de sus días.

Estos rasgos de afecto y respeto, él los tenía en mucha consideración, pero nunca mezcló el trato personal con el trato académico, tal vez por eso se le considerara en algunos ámbitos una persona demasiado rígida, y por supuesto, un poco terrorífico a la hora de los exámenes.

Aquéllos exámenes eran exhaustivos. Constaban de las tres pruebas tradicionales: una oral, una escrita y un ejercicio práctico de clasificación de material gráfico.

En conjunto, el ejercicio de cada alumno (ejercicios que eran individuales), solian durar alrededor de dos horas.

Esta exigencia venía impusta como consecuencia de una formación también exhaustiva, que no se reducía solamente a las horas normales lectivas, sino que se completaba con seminarios, prácticas de campo, e investigación de archivos.

La investigación y la docencia eran, como continúan siendo en el Laboratorio de Arte, los dos pilares del magisterio que ejercía Don Francisco Murillo.

Durante las vacaciones, siempre que tenía ocasión, viajaba al extranjero, principalmente a Alemania, donde se puso en contacto con los nuevos métodos de investigación en materias artísticas, métodos que fueron los que posteriormente puso en práctica en la Facultad de Sevilla. En ocasiones no viajaba solo, sino acompañado de algún alumno.

Para este profesor, los estudios de idiomas eran imprescindibles para una 
formación universitaria. En aquéllos principios de siglo, el alemán en primer lugar, seguido del francés y el italiano, eran lenguas imprescindibles para moverse en el campo de la investigación artística, y estas lenguas eran las que él dominaba.

Los viajes culturales también los realizaba durante el curso, en estos casos acompañando a sus alumnos, desplazándose a ciudades relativamente cercanas, para explicar «in situ» los principales monumentos artísticos.

Como vemos, unos métodos muy parecidos a los que hoy se practican, aunque probablemente de una eficacia mayor, debido a lo reducido del alumnado que entonces acudía a la Universidad.

Es fama entre sus discípulos que en clase demostraba una facilidad de palabra poco común y que su docencia resultaba, por supuesto instructiva, pero además muy amena. Así debieron ser también las conferencias que diera, aunque en este campo no se prodigara en exceso. A veces, daba alguna que otra charla cultural a instituciones y grupos de personas que no tenían un contacto directo con los medios culturales, pero su afán de llevar el Arte a toda clase de individuos, lo impelía a realizar estos actos altruistas.

Fuera del campo puramente docente, su prestigio indiscutible, provocó el que las consultas sobre temas de restauración, conservación del patrimonio artístico y en definitiva, todos los asuntos de peso en referencia al campo del arte, se conultaran con él.

Para la restauración de las vidriers de la Catedral de Sevilla, fue D. Francisco Murillo el que dió las pautas, encargándosele la dirección de las obras, en el aspecto científico-artístico.

Se inician las gestiones para este trabajo en 1928, aunque de hecho no empiezan las labores hasta 1929 , en que se adjudica el contrato a la Casa Maumejean, entidad de toda garantía que ya con anterioridad había realizado obras como las vidrieras de la Catedral Nueva de Vitoria, las de la Almudena de Madrid, las de la Cueva de San Ignacio de Manresa, las del Descubrimiento de América, en el Club Español de Buenos Aires y otras muchas más, entre ellas, y en la propia Sevilla, las del Ayuntamiento, en la reforma de 1917.

Además de Don Francisco Murillo, que prácticamente era el brazo ejecutor del proyecto, y que figuraba como Secretario de la Comisión de Restauración, era presidente de la misma el Sr. Arzobispo, por entonces, D. Eustaquio Illundain, y vocales del mismo organísmo, Don Carlos Cañal, Don Luciano Rivas y Santiago, Dean de la Catedral, Don Gonzalo Bilbao y Don Francisco Javier de Luque. Este último Catedrático Director de la Escuela Superior de Arquitectura de Madrid, y un buen amigo de Murillo Herrera.

Como invitado de honor a estas sesiones de la Comisión, solía asistir el Ilmo. Sr. Don Ramón Mélida, como asesor especial.

Grandes disgustos y esfuerzos costó al equipo llevar a cabo su empresa, pero sobre todo a D. Francisco, que con su rigor habitual, lo supervisaba todo, sin permitirse ni permitir el más mínimo fallo. 
Sus preocupaciones académicas también le absorbían por entonces parte de su tiempo, y no me refiero en esta ocasión solamente a la cuestión docente, que en ningún momento descuidó, sino al empeño que se había tomado en conseguir que el Gobierno de la Nación dotase a la Facultad de Filosofía y Letras de la Universidad Hispalense, de una nueva Cátedra de Historia del Arte.

En este caso, e impulsado el interés quizás por la Exposición Iberoamericana de 1929, se propuso con la titulación de "Arte Hispano-Colonial», y con esta denominación apareció concedida el 5 de Abril de 1930.

Su primer titular sería el joven discípulo de Don Francisco, y después prestigioso maestro, Don Diego Angulo Iñiguez, quien ya la ostentó con la denominación que actualmente se mantiene de «Historia del Arte Hispano-Americano».

Otras circunstancias también hicieron a Don Francisco Murillo dar su opinión respecto a conservación y protección de monumentos artísticos e históricos.

En ocasiones, el Estado Mayor del Ejército, también recurrió a su criterio, sobre todo con motivo de la contienda de 1936, para consultar qué obras, que por razones de estrategia estaban en peligro, debían ser por encima de todo respetadas, como fue el caso del Puente Romano de Córdoba.

También el Ayuntamiento y otros organismos oficiales le hacían frecuentes consultas a este respecto y las decisiones que tomaba Don Francisco, eran generalmente respetadas, como sucedió cuando hubo un intento de quitar la verja de la Fábrica de Tabacos, porque hubo quienes consideraban que por ser fundida y no de forja, tenía escaso valor, la negativa rotunda que dió para que se cometiera semejante desafuero nos permite ahora contemplar uno de los conjuntos dieciochescos más bellos de la ciudad.

En el aspecto urbanístico, también el Ayuntamiento sevillano tuvo el buen criterio de acudir a la opinión de Murillo Herrera. Se pretendía en este caso abrir una ámplia avenida que comunciara la Plaza del Salvador con la Plaza de la Encarnación, para lo que había que derribar la manzana de la izquierda de la Iglesia y el trazado de las calles Córdoba y Puente y Pellón. La destrucción de aquél conjunto, a la vista está que no se realizó, pues de haberse efectuado, la Plaza del Salvador, la que fuera decimononica plaza-salón, y una de las más características del «centro» de Sevilla, habría desparecido.

Un suceso que le dolió profundamente, fue la desestimación que el Cabildo Catedral de Sevilla, en tiempos del Cardenal Ilundain, hizo de su opinión acerca de la corona de la Virgen de la Antigua, de la Catedral.

La idea de superponer una corona de orfebrería a la que estaba pintada en el cuadro de Nuestra Señora, le pareció a nuestro experto un auténtico desatino. Sugirió que se empenachara el marco que cobijaba a la pintura, con la corona votiva, pero que de ninguna forma mutilaran la obra original. 
Esta sensata idea no tuvo buena acogida, y la pintura se taladró, se «enriqueció" y quedó como actualmente cualquiera puede contemplarla. Parece ser que este hecho marcó muy profundamente la sensibilidad artística de este experto.

Fue también hermano del Cachorro, y siempre lo veía pasar por el Puente, hasta sus últimos tiempos. Un año, no recordamos cual, el Hermano Mayor se acercó a Don Francisco y en esas palabras tan normales cuando pasa una Cofradía, le preguntó que qué le parecía como iba el paso del Cristo, y Murillo le contestó: «Muy bien, como siempre, pero le sobran los remates de oro de la Cruz». Y allí mismo, se dice, se los quitaron y nunca más se los han vuelto a poner. Puede que esto sea exagerado, pero es bonito.

Estos ejemplos que torpemente expreso, ponen de manifiesto, aunque innecesariamente, el prestigio que en la ciudad y fuera de ella, tenía D. Francisco Murillo Herrera.

Me cuentan que durante la Segunda Guerra Mundial pasó unos disgustos que hasta llegaban a ponerlo enfermo.

Cuando se enteraba de las terribles destrucciones que estaban padeciendo ciudades como Munich, Nuremberg, Berlin y tantas otras a las que él consideraba templos del Arte, se deprimía infinitamente, como si se tratara de una cuestión personal.

Para montar el Laboratorio de Arte, según las nuevas técnicas, una de las ciencias de las que tenía que surtirse era de la Fotografía. Era imprescindible un material gráfico manejable y que permitiera recopilar por medio de la imagen las obras de arte, para su estudio completo. Y sobre todo, para poner en conocimiento del alumnado estas mismas obras.

Así, Don Francisco, adquirió una máquina de fotografias especialmente hecha para él en Alemania, en la casa Ernemann (Dresde).

Con esta máquina alemana que respondía a la última tecnología de su momento, el fundador del Laboratorio de Arte de la Universidad de Sevilla, el primero en España y uno de los primeros de Europa de esta especialidad, realizó un número sin fin de diapositivas (las antiguas de cristal, que aún conservamos) y de fotografías, que él mismo revelaba en un laboratorio primitivo.

Pasaron muchos años hasta que esta labor de fotografía y revelado se le encomendó al Sr. González Nandín, uno de los más prestigios profesionales de Sevilla, al que con posterioridad siguieron otros en la labor de reproducción gráfica.

Para que este material tuviese una función didáctica, que es de lo que se trataba, era necesario un sistema de proyección, de manera que Don Francisco Murillo hizo traer de Alemania, allá por $1910 \mathrm{c}$. un enorme proyector, al que los antiguos del laboratorio conocemos como «El Gran Berta», una denominación que le dió nuestro recordado bedel, Ramón Blázquez, porque le parecía a aquel terrorífico cañón alemán de la Primera Guerra Mundial. 
Este aparato estaba fabricado por la ya citada Casa Ernemann de Dresde. Otro algo más reducido, al que llamaban «portatil», lo adquirió, como muchás piezas más, en la casa Leit-Wetlar, que al tener sucursal en Madrid, hacía más cómoda y fácil la distribución del material fotográfico.

Ambas piezas, junto con otras muchas de este tipo, se conservan en el Laboratorio de Arte.

Son múltiples las anécdotas de la vida profesional de Don Francisco que podríamos contar, pero todas no vendrían sino a reiterar su dedicación exhaustiva a la vida universitaria.

Paralelamente a la vida profesional, la vida particular de Don Francisco no fue muy fácil, aunque su estoicísmo le hacía tomarse las cosas con cierta tranquilidad.

A la muerte de su esposa, abandonó su domicilio en la calle Gravina, para ir a vivir con su madre a la calle Bailén. Cuando la madre falleció, se trasladó a la Pensión Sierpes, porque no quería ser gravoso a la familia. Esta pensión era un establecimiento que estaba cerca de la Universidad y de la Plaza del Salvador.

Durante algún tiempo vivió allí a pesar de la insistencia de su ahijado Paco, para que se trasladara a vivir con él en la Plaza del Salvador, en los altos de la Farmacia, donde tenían su casa el sobrino e Isaac el mancebo, a los que cuidaba una señora de edad que hacía las faenas domésticas.

Imposible era convencer a Don Francisco del nuevo cambio de domicilio, hasta que Don Francisco Murillo Campos, junto con Isaac, se presentaron en la Pensión Sierpes, le hicieron las maletas al «tito Paco», y lo trasladaron a vivir con ellos.

Allí se encontró muy a gusto. Después de su trabajo universitario se organizaban en la Farmacia pequeñas tertulias y además, tenía la comodidad de que estaba en su propia casa, sin necesidad de desplazarse.

En el año 1946, cuando el sobrino se casó, Don Francisco emigró de nuevo a otro domicilio, porque no quería estorbar a un matrimonio reciente.

No valieron para nada las consideraciones que se le hicieron, ni las muestras de afecto que recibió por parte de los novios.

El se fue a vivir a un piso en la Plaza de la Pescadería, donde vivió hasta su muerte. No obstante sus relaciones familiares, especialmente con su ahijado, siguieron siendo excelentes. Prueba de ello es que la pequeña tertulia, de cuyos recuerdos aún me estoy aprovechando hoy, siguió viva hasta que Don Francisco murió en 1951, y aún después, algunos de sus discípulos, sobre todo Don José Guerrero Lovillo, suele ir a charlar un rato con el actual propietario de la Farmacia, a esa deliciosa Rebotica de la Plaza del Salvador, como siguen yendo otras personas, entre ellos miembros de mi familia, que rememoran y cuentan historias antiguas de los tiempos de Don Francisco.

Precisamente a Don José Guerrero fué a quien Don Francisco regaló su medalla de Catedrático. Era de la época de Isabel II, y el maestro la tenía 
en un grán aprecio, aún así prefirió legarla al último de sus discípulos que había obtenido la Cátedra.

Pasó el tiempo, como siempre muy rápido, y en 1949 le llegó a Don Francisco la hora de jubilarse.

Después de haber sido durante un tiempo Director del Colegio Mayor de Santa María del Buen Aire, en Castilleja de Guzmán, a donde se desplazaba cada día sin importale gastos ni incomonidades, con tal que la reciente fundación marchara bien. Era el Colegio Mayor por excelencia de la Universidad de Sevilla, en cuya dirección le sustituiría muy pronto otro de sus mejores discípulos, Don Enrique Marco Dortas. Un poco cansado Don Francisco, dejó su Colegio en buenas manos.

Fue propuesto nuestro maestro como Académico de distintas instituciones de este tipo, pero siempre renunció, y nunca por desprecio ni dejadez, es que, sencillamente, la aceptaicón de esos honores le habría alterado su ritmo de vida.

Ya le había llegado la jubilación, pero su renombre era lo suficientemente conocido, para que el por entonces ministro de Educación, Don Elias Tormo, le propusiera ocupar otra cátedra, la de Geografía, en la misma Universidad de Sevilla, para poder así extender el tiempo de su docencia, y no separarlo bruscamente de su mundo habitual.

Ni que decir es menester, que Murillo Herrera rechazó de entrada semejante propuesta, alegando que si «por cuestiones de edad», ya no podía seguir impartiendo la materia a la que había dedicado tantos años, no había razón ninguna para que comenzara a enseñar una asignatura de la que no tenía sino nociones generales.

Asi es que en ese año de 1949, Don Francisco Murillo Herrera se despidió de su querida Cátedra de Historia del Arte de la Universidad de Sevilla.

La andadura posterior de este Maestro, entraría demasiado en lo circunstancial, por eso solamente queremos hacer ya una referencia a su muerte, no con ningún interés morboso, sino todo lo contrario. En su muerte también está su exaltación, y la justificación de toda su vida.

Cuando fue a morir, llamó a su sobrino-ahijado, y le dijo que lo enterraran con su esposa, pero él mismo había dispuesto, cuando ella falleció, que en su panteón no se inhumara ningún resto. Que nadie entrara en la tumba.

Ni él mismo pudo conseguirlo. El fué enterrado en el Panteón familiar, en cuyo marmol solamente se leé, «Familia Murillo».

Enemigo de honores y popularidad, la memoria de los humanos, a veces reconoce los valores de sus semejantes.

Hace algunos años, el Ayuntamiento de Sevilla le puso el nombre de Francisco Murillo a una calle de Sevilla, «cosa a la que - nos dice Murillo Campos- tito Paco se habría opuesto enérgicamente, lo mismo a que en el patio del Laboratorio de Arte se haya puesto una placa con su busto, y no menos se opondría, si estuviera vivo a la publicación de estas notas, de las que me 
creo culpable, por haberme asomado aunque someramente a su vida privada. Pero el mucho cariño que le profesé y profeso a su memoria, me ha impulsado, a mi también, a contrariarlo, y pienso y me consta su indulgencia, dado el gran cariño que siempre me tuvo».

Igual que Don Francisco Murillo Campos espera que su tio le perdone el haber puesto en mis manos unos datos personales para su publicación, espero yo que no tenga en cuenta mis indiscreciones al rebuscar en sus expedientes académicos, en su correspondencia, y en fín, en todo ese aparato que supone la confirmación de datos en una investigación, aunque ésta no sea todo lo profunda que merece Murillo Herrera*.

Pero por otra parte, considero un deber dedicar un recuerdo al que fue Maestro de tantos Historiadores del Arte, y sobre todo dar a conocer a los jóvenes miembros del Departamento de Arte de nuestra Universidad, tanto alumnos como profesores, quien fue la persona, sobre todo la persona, que hizo posible que el Laboratorio de Arte llegara a ser una realidad.

* Hernández Díaz, José. In Memoriam: Murillo Herrera Maestro Universitario (1878-1978). Bol. Academia Santa Isabel de Hungria. Sevilla, 1979. 


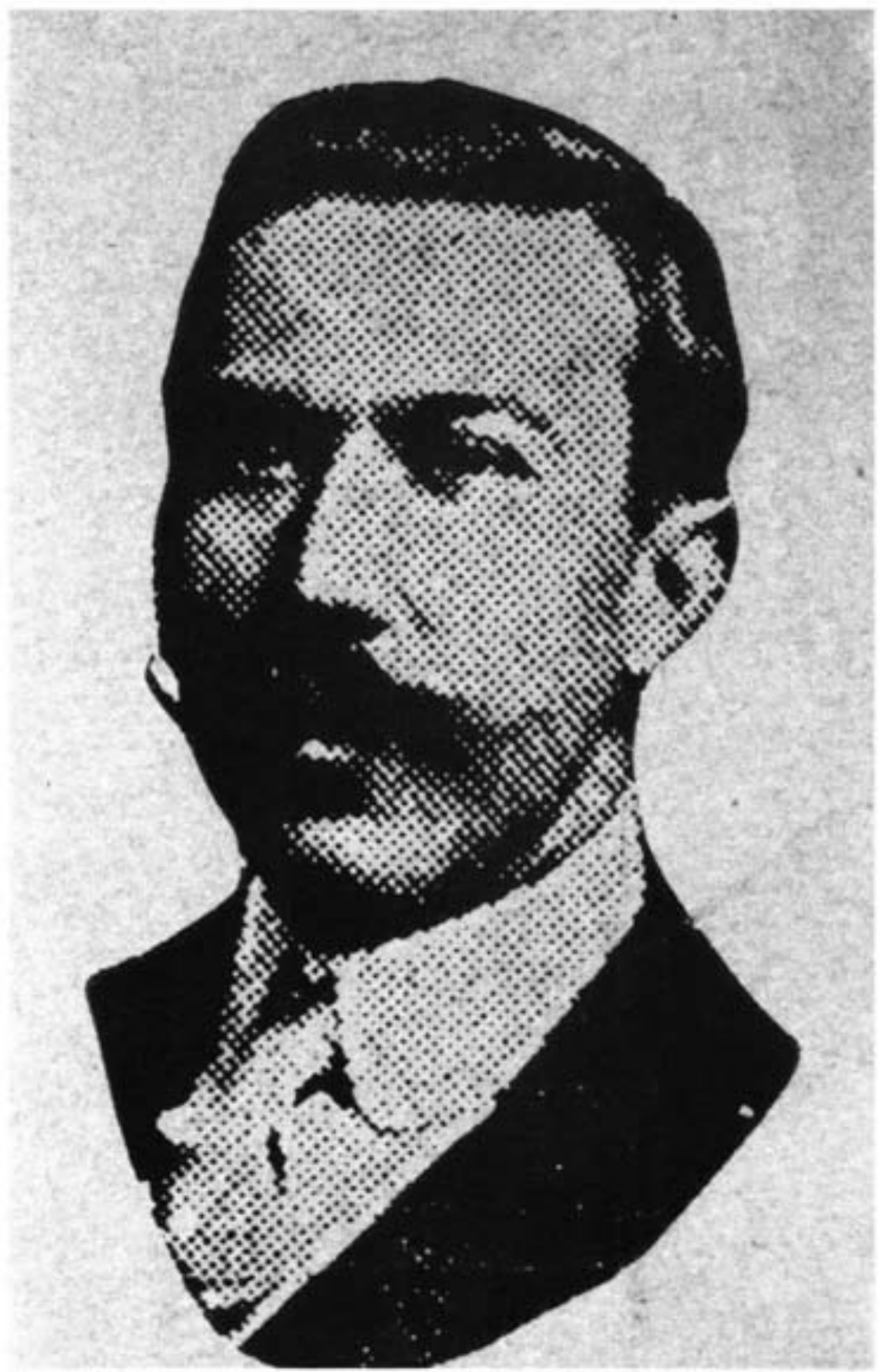

Don Francisco Murillo Herrera. Fotografia que aparece ilustrando una entrevista hecha a este Profesor, publicada en *El Liberals, el 30 de Mayo de 1925, cuando el Laboratorio de Arte se encontraba instalado en el Palacio de Arte Antiguo de la Exposición Ibero-Americana que se celebraría en 1929. 